\title{
A Review on the Hydrodynamic Characteristics of the SPP Concerning to the Available Experimental Data and Evaluating Regression Polynomial Functions
}

\author{
Seyyed Mostafa Seyyedi ${ }^{1}$, Rouzbeh Shafaghat ${ }^{2 *}$, Negin Donyavizadeh ${ }^{3}$ \\ ${ }^{1}$ PhD Student, Babol University of Tech.; Sea-Based Energy Research Group; Mostafa_5054@yahoo.com \\ ${ }^{2}$ Associate Prof., Babol University of Tech.; Sea-Based Energy Research Group; rshafaghat@nit.ac.ir \\ ${ }^{3}$ MSc, Babol University of Tech.; Sea-Based Energy Research Group; Negin_donya@yahoo.com
}

\section{ARTICLE INFO}

Article History:

Received: 27 May. 2018

Accepted: 14 Aug. 2018

\section{Keywords:}

Surface-piercing propeller

Propeller experimental test

Hydrodynamic coefficients

Regression relations

\begin{abstract}
Surface-piercing propellers have been widely used in light and high-speed vessels because of their superior performance. One of the major steps in propeller selection algorithm is the determination of thrust as well as torque hydrodynamic coefficients. For the purpose of simplifying design and selection procedure, some relations are presented for determining hydrodynamic coefficients in some studies, precision, and accuracy of which must be validated due to the importance of the issue as well as having high development and operational costs. Therefore, these issues are evaluated in this study by field study and recognizing the presented relation set as well as acquiring experimental test data. The acquired results show lack of full agreement between semi-experimental relations and experimental data. In the following, due to the limitations of the regression relations presented in the determination of hydrodynamic coefficients, the database was developed from experimental data, the number of series is determined by extracting the regression relations for each series, these relations are used to determine the hydrodynamic coefficient of thrust and torque in the propeller selection algorithm. Finally, a suitable algorithm for selecting the surface-piercing propeller was presented and discussed.
\end{abstract}

\section{Introduction}

The surface-piercing propeller is a special type of super-cavitation propeller that works in semiimmersion conditions. This type of propeller is designed to achieve the best performance and maximum efficiency at the highest speed. Due to some desirable features, the use of surface-piercing propeller has been widely used in lightweight and high-speed boats.

The first patent in the field of surface-piercing propellers happened in 1869. Since then, this type of propeller was utilized in hydroplanes and high-speed boats, gradually [1]. Utilizing submerged propellers in high-speed applications (more than 40 knots) requires some considerations due to destructive cavitation taking place [2]. For this reason, commercial and military marine industries indicate an increasing interest in utilizing surface-piercing propellers in high-speed applications, between 70 to 80 knots, nowadays [1]. Considering the distance of this type of propeller from the hull, its application is not limited to shallow waters and it is an appropriate propulsion system for high-speed crafts [3]. Reduced ship resistance, propeller's high efficiency as well as the possibility of increasing its diameter, and also reduced wet surface are the reasons of high efficiency of this propulsion system. Also, considering the fact that propulsion resistance forms $30 \%$ of total ship resistance [4], it increases the produced thrust and the propulsion efficiency leading to economized fuel consumption.

There's still a need for further study about this propeller type to realize its accurate practical performance as well as improving its performance due to lack of performed comprehensive research about this propeller type [5]. Memarian et al. [6], as well as Ghassemi et al. [5], presented determinative parameters in propeller selection process in distinct studies. These parameters include geometrical as well as physical specifications of the propeller. Numerous experimental studies are performed about the effects of these parameters on hydrodynamic performance of surface-piercing propellers, namely, Hadler's and 
Hecker's [7] in 1968, Rose's and Kruppa's [8] (1991), Olofsson's [9] in Sweden (1996), Dyson's [10] in the United States, Nozawa's and Takayama's [11] in Japan, Ferrando et al. [12-15] from 1996 to 2007 in Italy, Lorio's [16] in Atlantic university of America (2011), and Misra et al. [17] in India.

The algorithm for choosing the suitable propulsion system for a vessel involves specific processes for producing thrusts and increasing efficiency along with an important criterion for eliminating or reducing cavitation, which will be summarized in the design of the propeller and the choice of the engine. In general, for designing and selecting a propulsion system should consider all aspects (hydrodynamic, instrumental, economic, etc.) in order to ultimately provide the best efficiency. In addition to, the propeller design is a repeating cycle, its main purpose is to optimize the propeller efficiency by considering the design constraints that these design constraints vary depending on the type of vessel [18]. Therefore, it is important to study the thrust and torque generated by the propeller and its efficiency.

Based on the introduced design procedures for propeller selection [19], the most important stage is determining the values of minimum thrust and maximum allowed torque for the propeller via presented relations for hydrodynamic coefficients of thrust $\left(\mathrm{K}_{\mathrm{T}}\right)$ and torque $\left(\mathrm{K}_{\mathrm{Q}}\right)$.

Among these relations, the relations presented by Ferrando et al. [4] have attracted significant interest from the researchers. After their experimental studies, Ferrando investigated the effect of the parameters immersion ratio as well as pitch ratio on the thrust and torque coefficients as well as the propeller efficiency via presenting hydrodynamic relations based on experimental data [4]. In 2008, Montazeri and Ghassemi [4] presented a new second order regression model that considers more parameters for the hydrodynamic relations in their study via investigating experimental data presented in references $[4,8,9,11]$. In this paper, according to the important effects the hydrodynamic coefficients implement on the design and performance of surface-piercing propellers, the accuracy of these relations must be evaluated. Therefore, in this study, the effective parameters on the design and performance of surface-piercing propellers are comprehensively introduced and then the hydrodynamic relations presented in references [3, 4] are presented and compared with the available experimental data $[10,17]$.

After evaluating regression equations, appropriate solutions for determining of thrust and torque coefficients in order to development of an algorithm for selecting the surface-piercing propeller will be presented. According to the shortcomings of the hydrodynamic relations, it is proposed to obtain the hydrodynamic coefficients from a database of experimental data, instead of the regression equations. So, all existing experimental data has been collected, and 80 new regression relationship has been created. Finally, an algorithm for selecting the surface-piercing propeller for a vessel using experimental database will be described.

\section{Effective parameters on the design of the surface-piercing propeller}

The most important parameters effective on the behavior of surface-piercing propellers include geometrical specifications such as blade number ( $Z$ ), pitch ratio $(\mathrm{P} / \mathrm{D})$, expanded area ratio (EAR), rake angle $\left(\theta_{\mathrm{r}}\right)$, blade cross-section, as well as physical specifications such as shaft angle $\left(\theta_{\mathrm{s}}\right)$, advance ratio $(\mathrm{J})$, immersion ratio $\left(\mathrm{I}_{\mathrm{T}}\right)$ and also non-dimension numbers such as Reynolds ( Re), cavitation $(\sigma)$, Webber ( We), and Froude (Fr). Furthermore, two additional parameters namely yaw angle and skew angle are introduced as effective parameters on the performance of a surface-piercing propeller. Generally, effective parameters on hydrodynamic coefficients, $\mathrm{K}_{\mathrm{T}}$ and $\mathrm{K}_{\mathrm{Q}}$, for surface-piercing propellers are expressed as a function as follows [5]:

$$
\mathrm{K}_{\mathrm{T}}, \mathrm{K}_{\mathrm{Q}}=\mathrm{f}\left(\begin{array}{c}
\mathrm{Z}, \frac{\mathrm{P}}{\mathrm{D}}, \mathrm{EAR}, \theta_{\mathrm{r}}, \gamma, \psi, \\
\mathrm{J}, \mathrm{Fr}, \mathrm{Re}, \mathrm{We}, \sigma, \mathrm{I}_{\mathrm{T}}
\end{array}\right)
$$

Non-Dimensional numbers of cavitation, Froude, Webber, and Reynolds are the limitations and selection conditions among these parameters and the other parameters play the major role in calculating the values of hydrodynamic coefficients after these conditions are satisfied [3]. In the majority of performed experimental tests $[4,10,17]$, the value of immersion ratio that equals the value of immersed height divided by the propeller diameter, is acquired as $30-80$ percent. Also, yaw angle is important for the determination of lateral forces and affects the propeller efficiency as well as force variations. The domain of yaw angle is assumed to be within 0-30 degrees in the tests $[9,16]$. Fig. 1 shows the different propeller location angles.

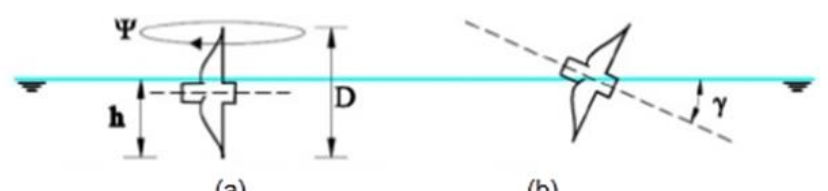

(a)

(b)

Figure 1. District of a)Yaw angle ( $\psi)$ and Immersion ratio

$$
\left(I_{T}=h / D\right) \text { b) Shaft angle }(\gamma)[19]
$$

The only performed test in the field of propellers having skew angle is Dyson's test [10], which was 
performed on three 4-blade propellers for three angles: $0.5,0$, and -0.5 radians,

Also, the effect of the geometry of propeller cross section is studied by Misra [17]. In his study, four different types of blade cross section at different Webber numbers are tested and a dozen series of an optimum cross section is developed.

\section{Surface-piercing propeller selection algorithm}

In the selection algorithm of a surface-piercing propeller, the goal is to determine the best surfacepiercing propellers for the high-speed boat. Each boat is designed to achieve a specific speed. The first step in designing propulsion system and selecting the appropriate propeller is to recognize and define the requirements.

In design, the following components must be satisfied:

1) Preparation required thrust

2) Achieving optimal torque

3) Achieving proper efficiency

4) Investigating the non-occurrence of cavitation with regard to the effects of the expanded area ratio

The design process of these propellers is influenced by more parameters than conventional propellers and includes the following general stages [20]:

1) Determining minimum required thrust as well as maximum allowable torque according to boat resistance at favorable speed $\left(\mathrm{V}_{\mathrm{A}}\right.$.)

2) Determining the engine speed $(n)$, gearbox ratio, and propeller diameter (D).

3) Determining the ranges of blade number $(Z)$, the expanded area ratio $\left(A_{E} / A_{0}=E A R\right)$, and pitch ratio $(\mathrm{P} / \mathrm{D})$.

4) Determining the ranges of yaw angle ( $\psi)$, shaft angle $(\gamma)$, immersion ratio $\left(\mathrm{I}_{\mathrm{T}}\right)$, and advance ratio $(\mathrm{J})$.

5) Calculating the values of thrust and torque via hydrodynamic coefficients of thrust $\left(\mathrm{K}_{\mathrm{T}}\right)$ and torque $\left(\mathrm{K}_{\mathrm{Q}}\right)$.

6) Investigating the limitations of cavitation, Webber, Reynolds, and Froude dimensionless numbers [21].

7) Selecting the propeller with maximum efficiency $(\eta)$ among favorable choices.

Fig. 2 shows a general algorithm for design and selection of surface-piercing propellers. In designing, it should be possible to reduce torque as much as possible and increase the thrust coefficient. The design process of surface-piercing propellers has input data including $\mathrm{V}_{\mathrm{A}}$ and $\mathrm{T}$, which $\mathrm{V}_{\mathrm{A}}$ is tin boat move mode with the desired design velocity and $\mathrm{T}$ is the propeller force at design velocity, which is obtained after calculating the boat resistance based on the results of the model test.

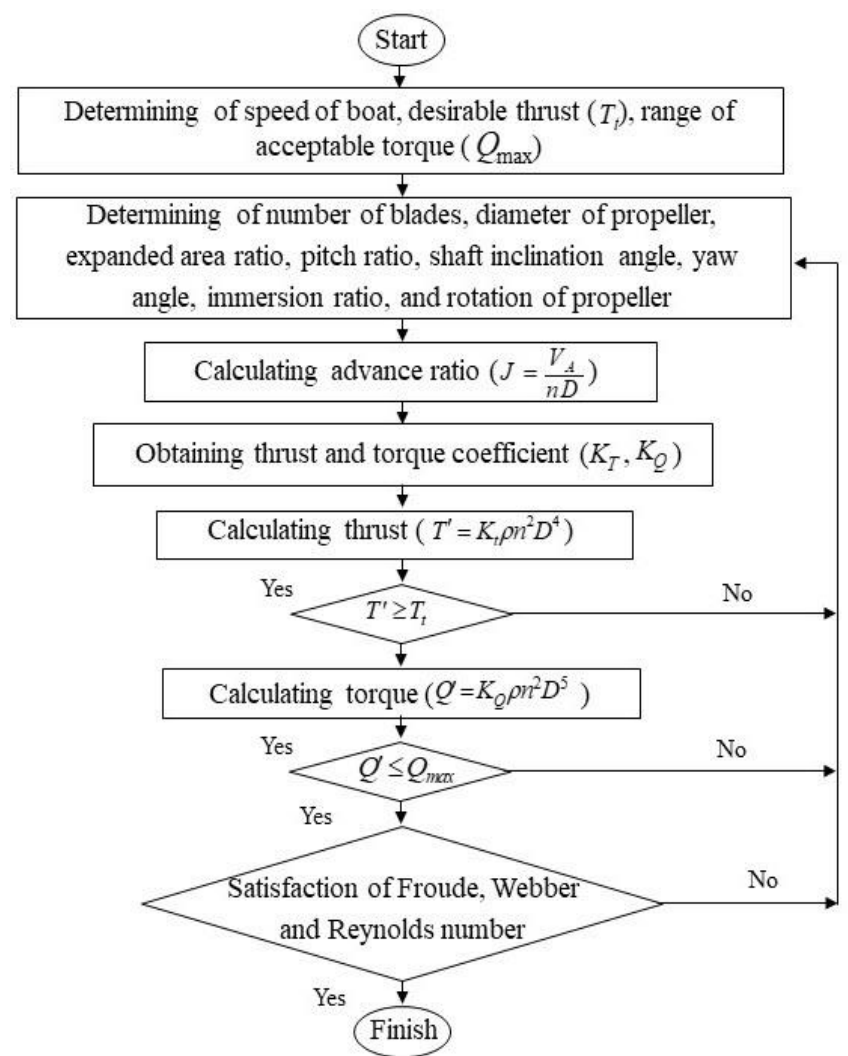

Figure 2. General algorithm for selecting the surface-piercing propeller

\section{Relations presented for hydrodynamic coefficients}

As explained before, determining hydrodynamic coefficients $\mathrm{K}_{\mathrm{T}}$ and $\mathrm{K}_{\mathrm{Q}}$ as well as $\eta$ (as the most important parameters in design and selection process of the propeller) are of great importance. In determining these relations, non-dimensional parameter variations are used for the purpose of reducing the number of the variables. In other words, some parameters are implemented separately. According to equation 2, instead of $\mathbf{J}$ as the advance ratio, $J_{\gamma}$ is used and consequently, the effect of shaft angle on the hydrodynamic coefficients is implemented in these relations.

$\mathrm{J}_{\gamma}=\frac{\mathrm{V}_{\mathrm{A}} \cos \gamma}{\mathrm{nD}}$

As expressed before, hydrodynamic coefficients of $\mathrm{K}_{\mathrm{T}}$ and $\mathrm{K}_{\mathrm{Q}}$ are functions of several parameters and for the purpose of reducing the effect of the parameter immersion ratio; these coefficients are expressed by regression functions as $\mathrm{K}_{\mathrm{T}}^{\prime}$ and $\mathrm{K}_{\mathrm{Q}}^{\prime}$.

Therefore, based on relations (3) to (5), these functions are acquired as multiplication of propeller submerged area ratio $\left(\mathrm{A}_{0}\right)$ and the propeller diameter squared. 


$$
\begin{aligned}
& \mathrm{K}_{\mathrm{T}}^{\prime}=\frac{\mathrm{T}}{\rho \mathrm{n}^{2} \mathrm{D}^{2} \mathrm{~A}_{0}} \quad, \quad \mathrm{~K}_{\mathrm{Q}}^{\prime}=\frac{\mathrm{Q}}{\rho \mathrm{n}^{2} \mathrm{D}^{3} \mathrm{~A}_{0}} \\
& \mathrm{~K}_{\mathrm{T}}=\frac{\mathrm{T}}{\rho \mathrm{n}^{2} \mathrm{D}^{4}}, \quad \mathrm{~K}_{\mathrm{Q}}=\frac{\mathrm{Q}}{\rho \mathrm{n}^{2} \mathrm{D}^{5}} \\
& \frac{\mathrm{K}_{\mathrm{T}}}{\mathrm{K}_{\mathrm{T}}^{\prime}}=\frac{\mathrm{K}_{\mathrm{Q}}}{\mathrm{K}_{\mathrm{Q}}^{\prime}}=\frac{\mathrm{A}_{0}}{\mathrm{D}^{2}} \\
& \frac{\mathrm{A}_{0}}{\mathrm{D}^{2}}=\frac{1}{4}\left(\frac{\pi}{2}-\operatorname{Arcsin}\left[\frac{0.5-\mathrm{I}_{\mathrm{T}}}{0.5}\right]\right), \mathrm{I}_{\mathrm{T}}=\frac{\mathrm{h}}{\mathrm{D}}
\end{aligned}
$$

In these relations, $\mathrm{Q}, \mathrm{T}, \mathrm{n}, \rho, \mathrm{h}$ represent torque ( N.m), propeller thrust ( $\mathrm{N})$, propeller rotation (rps), water density $\left(\mathrm{kg} / \mathrm{m}^{3}\right)$, and immersing depth of the propeller $(\mathrm{m})$, respectively. Presented relations for coefficients $\mathrm{K}_{\mathrm{T}}^{\prime}$ and $\mathrm{K}_{\mathrm{Q}}^{\prime}$ for the tested four blade and five-blade propellers used by Ferrando et al. [3] are as equations 6-7 and 8-9, respectively:

$$
\begin{aligned}
& \mathrm{K}_{\mathrm{T}}^{\prime}=-0.691625\left(\mathrm{~J}_{\gamma}\right)+0.794973\left(\frac{\mathrm{P}}{\mathrm{D}}\right) \\
& +0.870696\left(\mathrm{~J}_{\gamma}\right)\left(\frac{\mathrm{P}}{\mathrm{D}}\right)-0.395012\left(\mathrm{~J}_{\gamma}\right)^{2} \\
& -0.515183\left(\frac{P}{D}\right)^{2} \\
& 10 \mathrm{~K}_{Q}^{\prime}=-0.300453\left(\mathrm{~J}_{\gamma}\right)+0.543738\left(\frac{\mathrm{P}}{\mathrm{D}}\right) \\
& +0.877638\left(\mathrm{~J}_{\gamma}\right)\left(\frac{\mathrm{P}}{\mathrm{D}}\right)-0.649314\left(\mathrm{~J}_{\gamma}\right)^{2}-0.208974\left(\frac{\mathrm{P}}{\mathrm{D}}\right)^{2} \\
& \mathrm{~K}_{\mathrm{T}}^{\prime}=-0.61986\left(\mathrm{~J}_{\gamma}\right)+0.14553\left(\frac{\mathrm{P}}{\mathrm{D}}\right) \\
& +0.72956\left(\mathrm{~J}_{\gamma}\right)\left(\frac{\mathrm{P}}{\mathrm{D}}\right)-0.3049\left(\mathrm{~J}_{\gamma}\right)^{2}-0.12523\left(\frac{\mathrm{P}}{\mathrm{D}}\right)^{2} \\
& +0.28459 \\
& 10 \mathrm{~K}_{\mathrm{Q}}^{\prime}=-0.18468\left(\mathrm{~J}_{\gamma}\right)-1.20569\left(\frac{\mathrm{P}}{\mathrm{D}}\right) \\
& +0.69548\left(\mathrm{~J}_{\gamma}\right)\left(\frac{\mathrm{P}}{\mathrm{D}}\right)-0.56171\left(\mathrm{~J}_{\gamma}\right)^{2}+0.80543\left(\frac{\mathrm{P}}{\mathrm{D}}\right)^{2} \\
& +0.75101
\end{aligned}
$$

Therefore, the equation presented by Ferrando et al. [4] depends on five major parameters: blade number $(\mathrm{Z})$, pitch ratio $(\mathrm{P} / \mathrm{D})$, advance ratio $(\mathrm{J})$, shaft inclination angle $(\gamma)$, and immersion ratio $\left(\mathrm{I}_{T}\right)$. These equations are limited to tested propeller features as well as other test conditions and are expressed for 306 points, as listed in Table 1.
Table 1. Characteristics of the Propeller model test by Ferrando et al. [3]

\begin{tabular}{cc}
\hline Parameter & Range \\
\hline Number of Blades (Z) & 4,5 \\
Immersion Ratio (IT) & $0.4,0.5,0.6,0.7$ \\
Pitch Ratio (P/D) & $0.8,1.0,1.2$ \\
Expanded Area Ratio (EAR) & 0.67 \\
Shaft inclination angle & 6 \\
Yaw angle \& Skew angle & 0 \\
\hline
\end{tabular}

Also, Montazeri and Ghassemi [3] presented equations 10 and 11 for hydrodynamic coefficients of thrust and torque, respectively by performing a regression analysis upon 722 tested points of a surface-piercing propeller, presented in references $[4$, $8,9,11]$.

$$
\begin{aligned}
& \mathrm{K}_{\mathrm{T}}^{\prime}=-0.133-0.286 \mathrm{~J}_{\gamma}+0.507\left(\frac{\mathrm{P}}{\mathrm{D}}\right)+0.197\left(\frac{\mathrm{P}}{\mathrm{D}}\right)^{3} \\
& +0.164 \mathrm{~J}_{\gamma}{ }^{3}+0.564\left(\frac{\mathrm{P}}{\mathrm{D}}\right) \mathrm{J}_{\gamma} \mathrm{Z}-0.488\left(\frac{\mathrm{P}}{\mathrm{D}}\right)^{2} \mathrm{~J}_{\gamma} \\
& -0.176\left(\frac{\mathrm{P}}{\mathrm{D}}\right)^{2} \mathrm{Z}-0.28 \mathrm{~J}_{\gamma}^{2} \mathrm{Z}-0.601(\mathrm{EAR})^{2} \mathrm{~J} \\
& -0.021 Z^{2}\left(\frac{\mathrm{P}}{\mathrm{D}}\right)+0.175(\mathrm{EAR})^{2} \mathrm{Z} \\
& 10 \mathrm{~K}_{\mathrm{Q}}^{\prime}=0.12-1.12 \mathrm{~J}_{\gamma}+0.12\left(\frac{\mathrm{P}}{\mathrm{D}}\right)^{3}+0.34 \mathrm{~J}_{\gamma}^{3} \\
& +0.58\left(\frac{\mathrm{P}}{\mathrm{D}}\right) \mathrm{J}_{\gamma} \mathrm{Z}+0.07 \mathrm{Z}^{2} \mathrm{~J}_{\gamma}-0.08(\mathrm{Z})^{2}\left(\frac{\mathrm{P}}{\mathrm{D}}\right) \\
& +0.68(\mathrm{EAR})^{2}\left(\frac{\mathrm{P}}{\mathrm{D}}\right)-0.48 \mathrm{~J}_{\gamma}^{2} \mathrm{Z}-0.45\left(\frac{\mathrm{P}}{\mathrm{D}}\right)^{2}(\mathrm{EAR}) \\
& -0.44\left(\frac{\mathrm{P}}{\mathrm{D}}\right)^{2} \mathrm{~J}_{\gamma}+1.02\left(\frac{\mathrm{P}}{\mathrm{D}}\right)
\end{aligned}
$$

Therefore, these relations depend on 6 major parameters: pitch ratio $(\mathrm{P} / \mathrm{D})$, advance ratio $(\mathrm{J})$, shaft inclination angle $(\gamma)$, blade number $(Z)$, expanded area ratio (EAR), and immersion ratio $\left(\mathrm{I}_{\mathrm{T}}\right)$.

\section{Acquired results from hydrodynamic relations evaluation}

In this section, hydrodynamic coefficients of thrust and torque predicted by presented relations by Ferrando et al. [4] as well as Montazeri and Ghassemi [3] are compared with data acquired from experimental tests. Noting that test data presented by Dyson [10] and Misra et al. [17] are used in none of the mentioned studies, these data are used for 
validating these relations for all surface-piercing propellers. Dyson's and Misra's tests consist of 373 and 869 design points, respectively, as listed in Table 2. In order to evaluate and express the accuracy of these relationships, statistical analysis methods and Pearson correlation coefficient are used.

Table 2. Characteristics of the Propeller model test by Dyson [10] and Misra [17]

\begin{tabular}{ccc}
\hline Parameters & $\begin{array}{c}\text { Dyson test } \\
\text { range }\end{array}$ & $\begin{array}{c}\text { Misra test } \\
\text { range }\end{array}$ \\
\hline $\begin{array}{c}\text { Number of blade } \\
(\mathrm{Z})\end{array}$ & 4,5 & 4 \\
$\begin{array}{c}\text { Immersion Ratio } \\
(\mathrm{I} \text { ) }\end{array}$ & $0.3,0.5,0.8$ & $0.3,0.4,0.5,0.7$ \\
Pitch Ratio (P/D) & 1.52 & $0.8,1.0,1.2,1.4$ \\
$\begin{array}{c}\text { Expanded Area } \\
\text { Ratio (EAR) }\end{array}$ & $0.68,0.85$ & $0.45,0.6,0.7$ \\
Shaft angle & 4,8 & 5 \\
Skew angle & $-0.5,0,0.5$ & 0 \\
Yaw angle & $0,10,15$ & 0 \\
\hline
\end{tabular}

In order to evaluate and express the accuracy of these relationships, statistical analysis methods and Pearson correlation coefficient are used. A correlation coefficient is a statistical tool for determining the type and degree of the relationship of a quantitative variable with another quantitative variable. The correlation coefficient is one of the criteria used to determine the correlation between two variables, shows the severity of the relationship as well as the type of relationship (direct or inverse). This coefficient is defined in the interval $[-1,1]$ and is equal to zero in the absence of a relationship between the two variables. By expressing the qualitative correlation coefficient, the result is expressed in different intervals (Table 3).

Data from Dyson's test (propeller with 4, 5 blades) were compared with the acquired results of the values obtained through the Ferrando et al. [4] and Montazeri and Ghassemi [3] regression relations. This comparison is performed for all 373 design points and the results acquired from statistical analysis are presented in Table 4. According to these results, Ferrando's relation is more accurate for a 5 blade propeller in both thrust and torque coefficients. Also, for a 4 blade propeller, Montazeri's relation is more accurate than Ferrando's relation.
Table 3. Quality expression correlation coefficient

\begin{tabular}{|c|c|c|}
\hline $\begin{array}{l}\text { The Pearson } \\
\text { correlation } \\
\text { coefficient }\end{array}$ & $\begin{array}{c}\text { The relation } \\
\text { between the test } \\
\text { results and given } \\
\text { equation. }\end{array}$ & $\begin{array}{c}\text { Quality } \\
\text { expression }\end{array}$ \\
\hline$r<0.35$ & $\begin{array}{l}\text { Only } 4 \% \text { of the } \\
\text { variation between the } \\
\text { test results and the } \\
\text { given equation is the } \\
\text { same. }\end{array}$ & Weak \\
\hline $0.35<\mathrm{r}<0.65$ & $\begin{array}{l}\text { About } 25 \% \text { of the } \\
\text { variation between the } \\
\text { test results and the } \\
\text { given equation is the } \\
\text { same. }\end{array}$ & Intermediate \\
\hline $0.65<r<0.85$ & $\begin{array}{l}\text { To } 72 \% \text { of the } \\
\text { variation between the } \\
\text { test results and the } \\
\text { given equation is the } \\
\text { same. }\end{array}$ & Good \\
\hline $0.85<\mathrm{r}<1$ & $\begin{array}{l}\text { More than } 72 \% \text { of the } \\
\text { variation between the } \\
\text { test results and the } \\
\text { given equation is the } \\
\text { same. }\end{array}$ & Excellent \\
\hline
\end{tabular}

Table 4. Comparison Pearson correlation coefficient values of Ferrando and Montazeri regression equations with Dyson [10] experimental data

\begin{tabular}{cccc}
\hline $\begin{array}{c}\text { Number } \\
\text { of } \\
\text { Blade(Z) }\end{array}$ & $\begin{array}{c}\text { The Pearson } \\
\text { correlation } \\
\text { coefficient }\end{array}$ & $\begin{array}{c}\text { Ferrando } \\
\text { Eq }\end{array}$ & $\begin{array}{c}\text { Montazeri } \\
\text { Eq }\end{array}$ \\
\hline 4 & Thrust & $0.887(8)$ & $0.928(12)$ \\
\cline { 3 - 4 } & Torque & $0.914(9)$ & $0.937(13)$ \\
\hline 5 & Thrust & $0.904(10)$ & $0.798(12)$ \\
\cline { 3 - 4 } & Torque & $0.873(11)$ & $0.712(13)$ \\
\hline
\end{tabular}

Similarly, a comparison is performed between Ferrando's and Montazeri's relations using the data from Misra's test (Figs. 3 and 4). Since unlike the previous tests the advance ratio is assumed from zero in Misra's test, the advance ratio region is divided into several intervals for better comparison. According to the acquired diagrams, although the acquired results from Montazeri's relation have significant distance from real test values, it is found that their trend is more similar to the test results' trend and as the immersion ratio increases, this similarity becomes more obvious, whereas, for lower advance ratios, Ferrando's relation shows an absolutely opposite behavior relative to test data. 


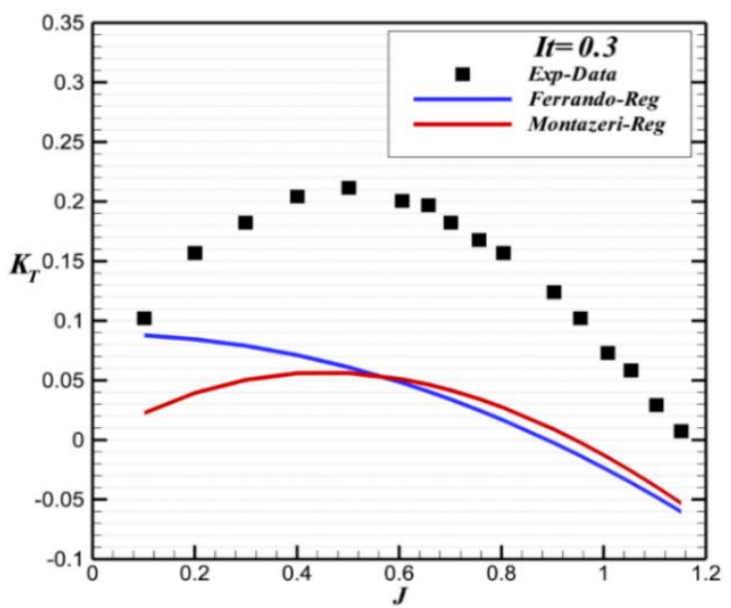

(a)

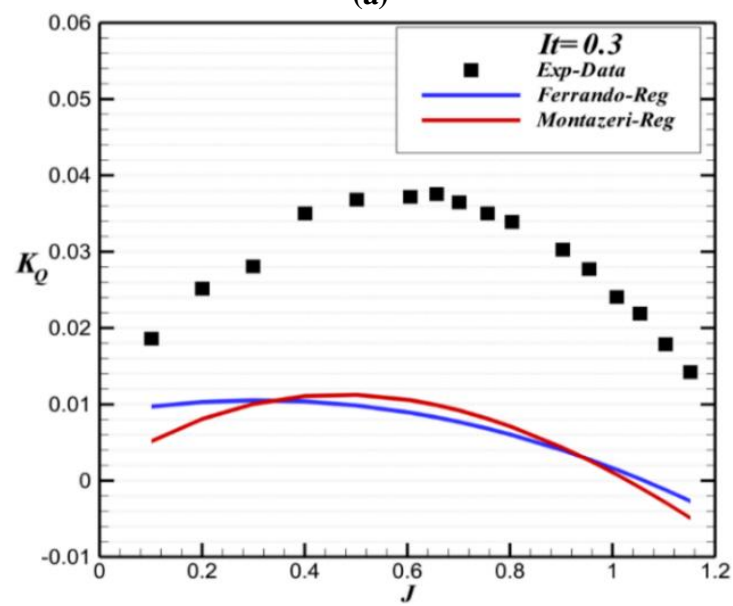

(b)

Figure 3. Comparison of the Ferrando and Montazeri regression equations with Misra's test values [17] in the immersion ratio of 0.3

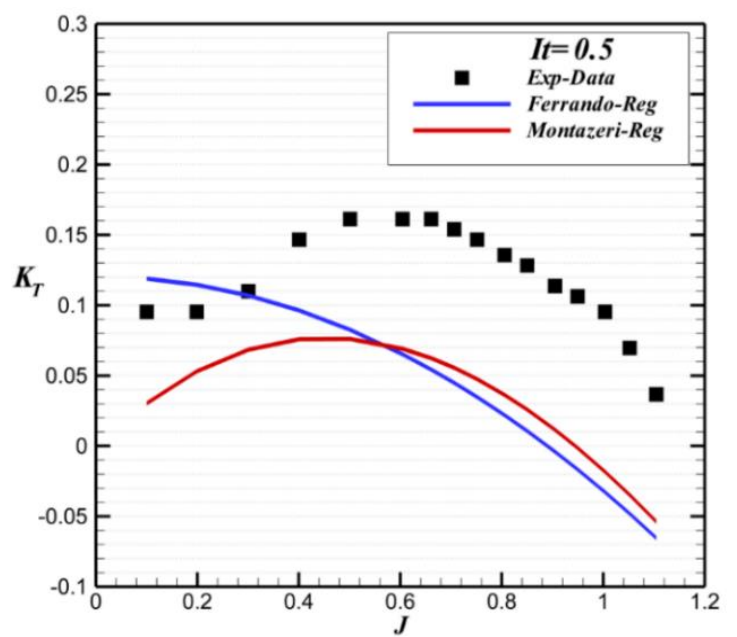

(a)

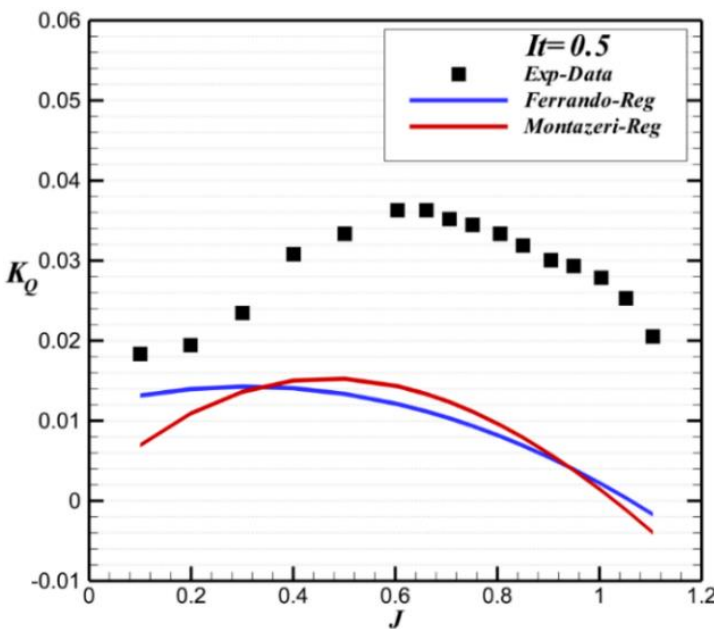

(b)

Figure 4. Comparison of the Ferrando and Montazeri regression equations with Misra's test values [17] in the immersion ratio of 0.5

In Table 5, the values of the Pearson correlation coefficient show the Ferrando and Montazeri regression relations in comparison with the Misra experimental data [17]. As it is shown in this table, for the thrust coefficient, Ferrando's relation shows an opposite behavior for advance ratios lower than 0.5, while Montazeri's relation shows a better behavior and as the advance ratio gets closer to 1 and exceeds it, both relations show an acceptable behavior. For torque coefficient, the behaviors of the two relations are much more similar as well as acceptable. It should be noted that these relations can only predict test data's trend and they can't provide accurate and acceptable information about the values of thrust and torque coefficients.

In an overall view point, the validity of these relations cannot be completely trusted due to significant differences between the relations' results and test data. This difference may be originated by the following reasons:

1) The uniqueness of these relationships is limited to a small number of empirical test data and makes limitation: Montazeri, in contrast to Ferrando, presented general constraints in presenting the hydrodynamic relations $(3 \leq \mathrm{Z} \leq 6,0.5 \leq \mathrm{EAR} \leq 0.8,0.5 \leq \mathrm{P} / \mathrm{D} \leq 2$, $0.1 \leq \mathrm{J} \leq 2)$; while there are no restrictions for Ferrando's relationships. 
Table 5. Comparison Pearson correlation coefficient values of Ferrando and Montazeri regression equations with Misra [17] experimental data

\begin{tabular}{|c|c|c|c|c|c|c|c|c|c|}
\hline \multirow{3}{*}{$\begin{array}{c}\text { Advance } \\
\text { ratio } \\
\text { (J) }\end{array}$} & \multirow[t]{3}{*}{$\mathbf{I}_{\mathbf{T}}$} & \multicolumn{2}{|c|}{$\begin{array}{l}\text { A correlation } \\
\text { coefficient of test } \\
\text { results with } \\
\text { ferrrando's } \\
\text { equation }\end{array}$} & \multicolumn{2}{|c|}{$\begin{array}{l}\text { A correlation } \\
\text { coefficient of test } \\
\text { results with } \\
\text { montazeri's } \\
\text { equation }\end{array}$} & \multicolumn{4}{|c|}{ Result } \\
\hline & & \multirow{2}{*}{ Thrust } & \multirow{2}{*}{ Torque } & \multirow{2}{*}{ Thrust } & \multirow{2}{*}{ Torque } & \multicolumn{2}{|c|}{ Thrust } & \multicolumn{2}{|c|}{ Torque } \\
\hline & & & & & & Ferrando & Montazeri & Ferrando & Montazeri \\
\hline \multirow{4}{*}{$0<\mathrm{J}<0.5$} & 0.3 & -0.932 & 0.702 & 0.858 & 0.855 & inverse & excellent & good & excellent \\
\hline & 0.4 & -0.913 & 0.516 & 0.608 & 0.716 & inverse & intermediate & intermediate & good \\
\hline & 0.5 & -0.886 & 0.462 & 0.528 & 0.677 & inverse & intermediate & intermediate & good \\
\hline & 0.7 & -0.799 & 0.174 & 0.366 & 0.644 & inverse & intermediate & weak & intermediate \\
\hline \multirow{4}{*}{$0.5<\mathrm{J}<1$} & 0.3 & 0.99 & 0.959 & 0.998 & 0.977 & excellent & excellent & excellent & excellent \\
\hline & 0.4 & 0.979 & 0.926 & 0.996 & 0.951 & excellent & excellent & excellent & excellent \\
\hline & 0.5 & 0.964 & 0.845 & 0.989 & 0.88 & excellent & excellent & good & excellent \\
\hline & 0.7 & -0.173 & -0.54 & -0.164 & -0.539 & inverse & inverse & inverse & inverse \\
\hline \multirow{4}{*}{$1<\mathrm{J}$} & 0.3 & 0.995 & 0.997 & 0.996 & 0.997 & excellent & excellent & excellent & excellent \\
\hline & 0.4 & 0.993 & 0.988 & 0.993 & 0.988 & excellent & excellent & excellent & excellent \\
\hline & 0.5 & 0.999 & 0.991 & 0.999 & 0.992 & excellent & excellent & excellent & excellent \\
\hline & 0.7 & 0.998 & 0.999 & 0.998 & 0.999 & excellent & excellent & excellent & excellent \\
\hline
\end{tabular}

2) Different conditions in the tests: Given that the semi-experimental relations are the result of the analysis of the experimental results, the differences in the test conditions may be due to the difference and the invalidity of the relationship. One of the important issues not mentioned in any of the experiments is the type of section used in the model propeller, in which the cross-section parameter has not been used to create of relationship, and if there is a difference between the sections used, the relationship loses their generalizability.

3) The low accuracy of the relationship is related to the effect of the immersion ratio parameter.

\section{Limitations of presented hydrodynamic relations}

One of the major noteworthy issues about every regression relation is its limitations. Unlike Ferrando, Montazeri expressed the general limitations while along with presenting hydrodynamic relations $(0.5 \leq$ P/D $\leq 2 ، 0.5 \leq$ EAR $\leq 0.8 ، 3 \leq \mathrm{Z} \leq 6$ ). Fig. 5 shows the acquired diagrams of regression relations of Ferrando and Montazeri, according to the limitation of advance ratio as being more than 0.5 . This diagram is for a four blade propeller with immersion ratio as 0.5 , pitch ratio as 1.2 , and area ratio as 0.67 .

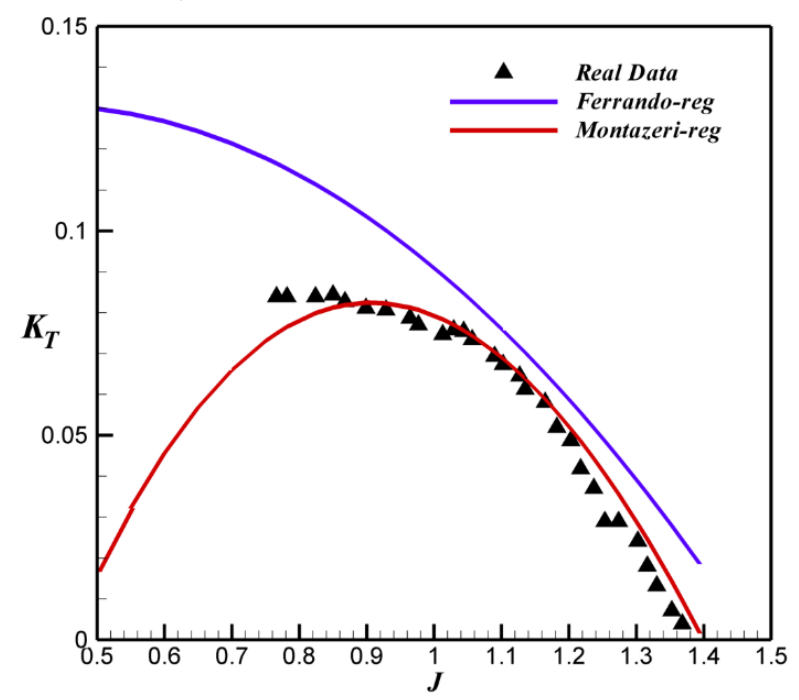

Figure 5. Prediction of hydrodynamic equations in the defined range

It is found from Fig. 5 that at advance ratios out of the range of each diagram, unreasonable results are acquired by mathematical analysis and due to the definition of these results in the range of propeller selection, an unreal outcome will be acquired, definitely. Therefore, this issue is one of the 
shortcomings of these relations and to overcome this weakness, the definition range should become smaller. Another shortcoming of these relations is excluding the effect of some parameters such as skew angle, yaw angle, and cross section effect. Skew angle is a geometrical feature of the propeller which although is straight and zero for most of the propellers, but it is necessary to consider it for the design and manufacture processes. Furthermore, the yaw angle depends on how the propeller is installed and oriented and deserves significant care $[10,16]$.

\section{Development of an experimental database for selection of surface-piercing propeller}

As mentioned in the previous section, the hydrodynamic relations presented have limitations and shortcomings in obtaining hydrodynamic coefficients; considering the high importance of determining the hydrodynamic coefficients of the thrust and the torque in the process of designing the surface-piercing propeller and the existence of some weaknesses and deficiencies in the regression relations presented, on the basis of this study, after completing the database of the experimental data, it is possible to more precisely determine the coefficients hydrodynamics is investigated. Due to the development of the database using data from additional experimental Research, the direct use of this database for analysis and design has a higher reliability than existing semi-experimental relationships.

In this regard, tried to collect and analyzed all existing experimental data. Firstly, begin to field study and identifying all experimental research on the surfacepiercing propeller, and then for collecting the data from these experiments, the graphs of the results of each experiment and the information in each graph are used as a whole (Appendix A). After extraction of all of the points from experimental test modes, all of these data are classified according to the test cases from 1 to 80 . The characteristics of the series from 1 to 10 are listed in Table 6.

After extraction of data, due to the difference in the advance ratio $(J)$ in different series, it is necessary to equalize the progress coefficients for better examination and a more comprehensive comparison between the series. For this, the interpolation method is used such that the values $\left(\mathrm{K}_{\mathrm{T}}\right)$ and $\left(\mathrm{K}_{\mathrm{Q}}\right)$ in the advance ratio of 0.1 to 1.6 with a distance of 0.1 are determined for all series.
Table 6. Characteristic of surface-piercing propeller series

\begin{tabular}{ccccccccc}
\hline $\begin{array}{c}\text { Serie } \\
\mathbf{S}\end{array}$ & $\mathbf{Z}$ & $(\mathbf{P} / \mathbf{D})$ & $(\mathbf{E A R})$ & $\left(\theta_{\mathbf{r}}\right)$ & $\left(\theta_{\mathbf{r}}\right)$ & $(\gamma)$ & $(\psi)$ & $(\mathbf{I t})$ \\
\hline 1 & 3 & 1 & - & - & - & 0 & 0 & 0.33 \\
2 & 3 & 1.3 & - & - & - & 0 & 0 & 0.33 \\
3 & 3 & 1.6 & - & - & - & 0 & 0 & 0.33 \\
\hline 4 & 4 & 0.8 & 0.45 & - & - & 5 & 0 & 0.3 \\
5 & 4 & 1 & 0.45 & - & - & 5 & 0 & 0.3 \\
6 & 4 & 1.2 & 0.45 & - & - & 5 & 0 & 0.3 \\
7 & 4 & 1.4 & 0.45 & - & - & 5 & 0 & 0.3 \\
\hline 8 & 4 & 0.8 & 0.45 & - & - & 5 & 0 & 0.4 \\
9 & 4 & 1 & 0.45 & - & - & 5 & 0 & 0.4 \\
10 & 4 & 1.2 & 0.45 & - & - & 5 & 0 & 0.4 \\
\hline
\end{tabular}

In this case, the results of all the series data can be evaluated on specific advance ratios. In Table (7) interpolate sample is shown for one series 4 .

Table 7. Interpolation of hydrodynamic coefficients in terms of the advance ratio for series 4

\begin{tabular}{cccc}
\hline Number & $\begin{array}{c}\text { Advance ratio } \\
(\mathbf{J})\end{array}$ & $\begin{array}{c}\text { Thrust } \\
\text { coefficient } \\
\left(\mathbf{K}_{\mathbf{T}}\right)\end{array}$ & $\begin{array}{c}\text { Torque } \\
\text { coefficient } \\
\left(\mathbf{K}_{\mathbf{q}}\right)\end{array}$ \\
\hline 1 & 0.1 & 0.1415 & 0.02308 \\
2 & 0.2 & 0.162 & 0.0273 \\
3 & 0.3 & 0.1916 & 0.03322 \\
4 & 0.4 & 0.222 & 0.0393 \\
5 & 0.5 & 0.237 & 0.0438 \\
6 & 0.6 & 0.234 & 0.0459 \\
7 & 0.7 & 0.2112 & 0.04675 \\
8 & 0.8 & 0.1851 & 0.04744 \\
\hline
\end{tabular}

To determine the hydrodynamic coefficients from the experimental database, the regression analysis based on experimental data is performed using the "SPSS" statistical analysis software and the emergence of new regression relationships. For regression analysis, 80 series of propellers are used, and instead of achieving a comprehensive relationship for all series, for each series, independently, a regression relationship is presented.

Since each series has a series of points with the same test data contents (such as shaft inclination angle, Skew angle, Yaw angle, immersion ratio, pitch ratio, expanded area ratio, etc.) and different hydrodynamic coefficients $\left(K_{T}, K_{Q}, \eta\right)$ in terms of different advance ratio $(\mathrm{J})$, which can be used instead of a set of points (more than 1500 points) of a series of curves (80 
series) that is figure of these points within a defined range of advance ratio.

Therefore, using this software, these series of regression analyzed and their torque and thrust hydrodynamic coefficients relations based on the Sixth-degree equations are obtained in terms of the advance ratio for the thrust coefficient and the fourthdegree equation for the torque coefficient in terms of the advance ratio:

$$
\begin{aligned}
& \mathrm{K}_{\mathrm{T}}=\mathrm{a}_{\mathrm{T}} \mathrm{J}^{6}+\mathrm{b}_{\mathrm{T}} \mathrm{J}^{5}+\mathrm{c}_{\mathrm{T}} \mathrm{J}^{4}+\mathrm{d}_{\mathrm{T}} \mathrm{J}^{3}+\mathrm{e}_{\mathrm{T}} \mathrm{J}^{2} \\
& +\mathrm{f}_{\mathrm{T}} \mathrm{J}+\mathrm{g}_{\mathrm{T}} \\
& \mathrm{K}_{\mathrm{Q}}=\mathrm{a}_{\mathrm{Q}} \mathrm{J}^{4}+\mathrm{b}_{\mathrm{Q}} \mathrm{J}^{3}+\mathrm{c}_{\mathrm{Q}} \mathrm{J}^{2}+\mathrm{d}_{\mathrm{Q}} \mathrm{J}+\mathrm{e}_{\mathrm{Q}}
\end{aligned}
$$

For series 2 and 3, the regression relationships are based on the experimental data, as follows:

$$
\begin{aligned}
& \mathrm{K}_{\mathrm{T}}=0.4427 \mathrm{~J}^{4}-2.0753 \mathrm{~J}^{3}+3.5937 \mathrm{~J}^{2}
\end{aligned}
$$

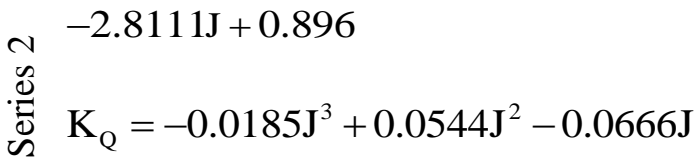

$$
\begin{aligned}
& +0.0424
\end{aligned}
$$

$$
\begin{aligned}
& \mathrm{K}_{\mathrm{T}}=-7.349 \mathrm{~J}^{6}+57.601 \mathrm{~J}^{5}-186.21 \mathrm{~J}^{4} \\
& \text { m }-317.63 \mathrm{~J}^{3}-301.38 \mathrm{~J}^{2}+150.67 \mathrm{~J} \\
& \text { : } \\
& -30.894 \\
& \mathrm{~K}_{\mathrm{Q}}=0.0247 \mathrm{~J}^{3}-0.1033 \mathrm{~J}^{2}+0.1244 \mathrm{~J} \\
& -0.0271
\end{aligned}
$$

Using the designed algorithm (Fig. 6), the database of experimental test data and regression relations, and its coefficients can select a suitable propeller for a vessel. In other words, the purpose of the algorithm is to select the appropriate propeller with the maximum efficiency for a vessel.

In this algorithm, the input information includes vessel speed $\left(\mathrm{V}_{\mathrm{A}}\right)$, vessel resistance $\left(\mathrm{T}_{\mathrm{t}}\right)$, engine power (P). This algorithm consists of three iteration loops and covers all possible combinations for design. The first loop is the rotation of the propeller which starts with $\mathrm{n}_{1}$ and ends in $\mathrm{n}_{\max }$, and the rotation step is step ${ }_{1}$. The second and third loop is placed inside this loop and the second loop will be repeated for each $\mathrm{n}$. The second loop is the propeller diameter, which starts with $D_{1}$ and leads to $D_{\max }$, and the step od diameter is step $_{2}$. The third loop is inside this loop, and this loop will be repeated for each diameter of the propeller, the second loop will be repeated. The third loop is the number of series of propellers shown with $\mathrm{K}$, starting

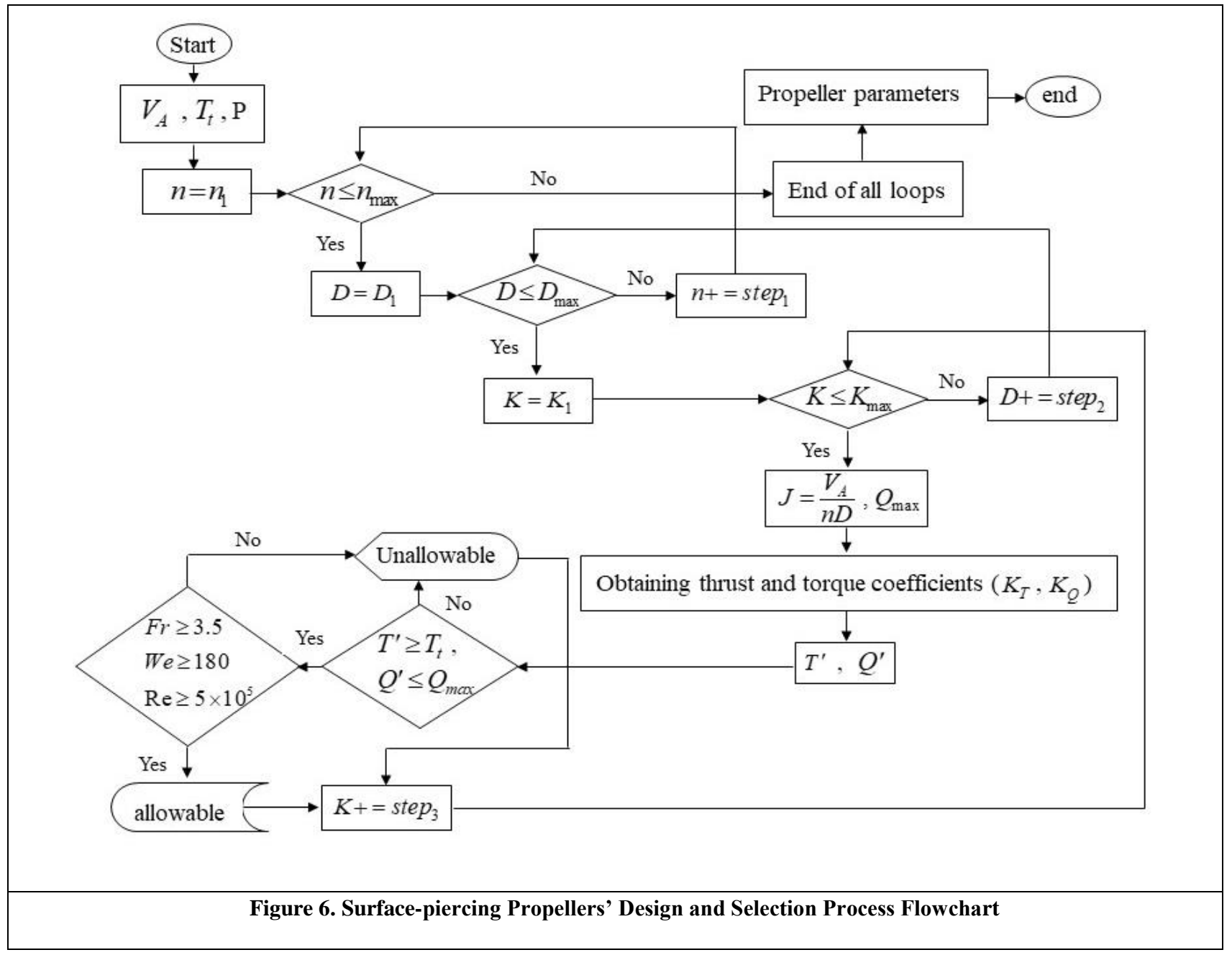


from $K_{1}$ to $K_{\max }$, and the step is step $_{3}$. In this algorithm, instead of semi-experimental relations for determining of thrust and torque coefficients, regression relationships obtained from 80 series of propellers has been used. It can provide the number of favorable states which can produce the minimum required thrust for vessel motion, not exceed the maximum torque and satisfied Froude, Webber, and Reynolds number. Thereafter, a few superior modes that have the highest efficiency are selected based on the set series as the best modes. According to number of series, characteristics of selected propeller includes the number of blades $(\mathrm{Z})$, the pitch ratio $(\mathrm{P} / \mathrm{D})$, expanded area ratio (EAR), Rake angle, shaft angle, Yaw angle, immersion ratio $\left(\mathrm{I}_{\mathrm{T}}\right)$, and Diameter of propeller (D) to be determined.

\section{Conclusion}

Considering the major role of the propeller in the behavior of high-speed boats, achieving technical knowledge of designing surface-piercing propellers is one of the most important discussions about the design process of high-speed boats. In this study, considering the important effects of hydrodynamic coefficients on the design and propeller selection, regression relations presented by Ferrando and Montazeri for surface-piercing propellers are investigated and their accuracy and validations, as well as shortcomings and limitations, are discussed. Then, considering that the semi-experimental relations presented have limitations in determining the hydrodynamic coefficients, using the experimental data of different tests, a database was created from these data and the hydrodynamic coefficients in the algorithm of selecting of the surface-piercing propeller were determined by the experimental database. Using the designed algorithm, a suitable propeller for a vessel is selected that has the highest efficiency.

The major achievements of this study are as follows:

- The investigations show that Montazeri's relation to determining the hydrodynamic coefficient is more accurate than Ferrando's; however, none of them have sufficient accuracy compared to experimental results.

- The semi-experimental relations are not trustworthy in different geometrical conditions and they cannot be used in the design process.

- For further improving the relations, it is necessary to discuss the effect of some of the parameters such as yaw angle, skew angle, and cross section effect.

- One of the major weaknesses of semiexperimental relation is the lack of accurate determination of the design region which can lead to an unreal design point selection.
- In this study, using experimental data from various researchers, the database created various test data and the algorithm and code corresponding to select the appropriate propeller that satisfies all the required conditions.

- Due to the use of the exact information of the tests performed in this study, the errors are only related to the testing. While using semiexperimental relationships in addition to the test error, there is also an error in choosing a relationship.

\section{References}

1- B. S., Yin Lu Young, and M. S., (2002), Numerical Modeling of Supercavitating and Surface-Piercing Propellers, Report No. 02-1 Thesis (Ph. D.), Department of civil engineering, The university of Texas at Austin, TX 78712, Environmental and water resources engineering.

2- Yangajeh, M.A, Seif, M.S. and Mehdigholi, H., (2009), Determination of propeller speed in experimental model of surface-piercing propeller, 11th international conference of Iranian marine industries, Kish island. (In Persian)

3- Montazeri, N. and Ghassemi, H., (2009), Determination of hydrodynamic coefficients of the surface-piercing propeller by regression method, 6th annual conference of design principles and applications of high-speed craft, chaloos, Iran.(In Persian)

4- Ferrando, M., (2007), Performance of family of surface piercing propellers, pp. 63-70.

5- Ghassemi, H., Hassanvand, M., Nazari, A., Hashemi, H., and Ghasabzade, M., (2009), Hydrodynamic analysis of Surface-piercing propeller, 6th annual conference of design principles and applications of high-speed craft, chaloos, Iran.(In Persian)

6- Memarian, H., Zeraatgar, H., Bakhshande rostami, A., (2009), Designing of the surface-piercing propeller for a high-speed craft, 11th international conference of Iranian marine industries, Kish island Iran. (In Persian)

7- Hadler, J.B., and Hecker, R., (1968), Performance of Partially Submerged Propellers, Proc 7th ONR Symposium on Naval Hydrodynamics, Rome.

8- Rose, J.C., and Kruppa, C. F., (1991), Methodical Series Model Test Results, FAST,91," Trondheim, Norway. Procs. Publ by Tapir Publishers, Trondheim, vol. 2, p. 1129.

9- Olofsson, N., (1996), Force and flow characteristics of a partially submerged propeller, Doctoral Thesis, Department of Naval Architecture and Ocean Engineering, Goteborg: Chalmers University of Technology. 
10- Dyson, P.K., (2000), Modelling, testing and design, of a surface piercing propeller drive.

11- Nozawa, K., (2002), Hydrodynamic Performance and Exciting Force of SPP.

12- Ferrando, M., and Scamardella, A., (1996), Surface Piercing Propellers: Testing Methodologies,

Result Analysis and Comments on Open Water Characteristics, pp. 1-27.

13- Ferrando, M., (1997), Surface piercing propellers: state of the art, Oceanic Eng. International, 1(2): 4049.

14- Ferrando, M., and Scamardella, (1999), Surfacepiercing propellers: model tests procedures and comments on related a dimensional parameters, Proceedings 5th Symposium on High-Speed Marine Vehicles, Capri, 24-26.

15- Ferrando, M., Viviani, M., Crotti, S., Cassella, P., Caldarella, S., (2006), Influence of Weber number on Surface Piercing Propellers model tests scaling, Proceedings of 7 th International Conference on Hydrodynamics (ICHD), Ischia, 4-6.

16- Lorio, J.M., (2011), Open Water Testing of a Surface Piercing Propeller with Varying Submergence, Yaw Angle and Inclination Angle,
Master of Science in Ocean Engineering, The College ofjabia Engineering and Computer Science, Boca Raton, Florida.

17- Misra, S.C., Gokan, R.P., Sha, O.P., Suryanarayana, Ch., and Suresh, R.V., (2012), Development of a Four-Bladed Surface Piercing Propeller Series Naval Engineering Journals, No. 124-4.

18- Carlton, J., (2007), Marine propellers and propulsion, Second edition, Butterworth-Heinemann.

19- Rajabiani, E., Imantalab, A., (2009), Mathematical analysis of a new model of the surfacepiercing propeller by finite element method," national conference of maritime and shipping , chabahar, Iran.(In persian)

20- Donyavizadeh, N., Shafaghat, R., and Seyyedi, S.M., (2016), Development of surface-piercing propeller selection algorithm," 17th international conference of iranian marine industries, kish island. (In persian)

21- Pustoshny, A.V., Bointsov, V.P., Lebedev, E.P., and Stroganov, A., (2007), Development of 5-blade SPP series for fast speed boat Ninth international Conference on Fast Sea, Shanghai. 